\title{
MINIMIZAÇÃO DA INTENSIDADE ENERGÉTICA DA ÁGUA UTILIZADA EM UMA RESIDÊNCIA
}

\section{Thiago Barbosa ${ }^{1}$; Bruna Katarina Azevedo ${ }^{2}$;Eduardo Cohim $^{3}$}

1. Thiago Barbosa, Departamento de Tecnologia, Programa de Pós-Graduação em Engenharia Civil e Ambiental, Universidade Estadual de Feira de Santana, e-mail: thg.brbs@gmail.com

2. Bruna Katarina Pereira de Azevedo, Graduanda em Engenharia Civil, Universidade Estadual de Feira de Santana, email: brunakatarina14@gmail.com

3. Eduardo Cohim, Departamento de Tecnologia, Universidade Estadual de Feira de Santana, e-mail: edcohim@gmail.com

PALAVRAS-CHAVE: Uso racional de água; fontes de abastecimento; análise quantitativa

\section{INTRODUÇÃO}

A água é um recurso limitado, e atualmente encontra-se em situação de escassez. Objetivando preservar os mananciais, fontes alternativas de água têm sido cada vez mais usadas em substituição da água potável vinda da concessionária. As principais são a água cinza tratada, a água de chuva e a água subterrânea.

Segundo o conceito de Metabolismo Urbano, recentemente definido por Renouf et al. (2016) e a partir de analogias onde os modelos de metabolismo urbano quantificam as entradas, saídas e estoques de energia, água, nutrientes e materiais e oferecem aos responsáveis informações essenciais sobre o impacto de suas decisões, nota-se que água e energia são recursos que estão interligados. A água é utilizada em praticamente todos os processos de geração de energia e a esta, por sua vez, é indispensável nos processos de captação, tratamento, distribuição e uso da água. Em resumo, são recursos interdependentes, que precisam ser analisados em conjunto, de forma mais integrada.

Segundo Soares et. al (2017) a indústria da água é um grande consumidor de energia, desde a fase de construção das instalações, a de operação até a final desmobilização do equipamento. A maior parte da energia é consumida no transporte e elevação da água. A eletricidade é a forma predominante de energia e é utilizada para alimentar bombas, válvulas, compressores e outro equipamento. Em 2016, as despesas com energia elétrica dos prestadores de serviço de saneamento participantes do SNIS atingiram $\mathrm{R} \$ 5,41$ bilhões, tendo sido consumidos 11,8 TWh, compostos por 10,6 TWh com abastecimento de água e 1,2 TWh com esgotamento sanitário (SNIS, 2018).

Em geral, dada a descentralização, as fontes alternativas de água têm encargo energético inferior ao da agua de abastecimento público, embora não possuam grau de potabilidade. Desse modo, podem ser usadas em atividades de menor exigência qualitativa.

O objetivo deste estudo é avaliar a minimização da energia incorporada na água para abastecimento em uma residência através do uso de diversas fontes com distintas intensidades energéticas.

\section{MATERIAL E MÉTODOS OU METODOLOGIA}

Este estudo tomou como base uma residência com área de telhado de $100 \mathrm{~m}^{2}$ e uma área permeável de $280 \mathrm{~m}^{2}$. Os dados de usos finais foram obtidos por Cohim e Cajazeiras (dados não publicados) em uma residência com 5 pessoas, podendo ser vistos na Tabela 1:

Tabela 1-Consumo diário de água em uma residência

\begin{tabular}{ccccccccc}
\hline Usos & Beber & Chuveiro & Lavatório & $\begin{array}{c}\text { Lav. } \\
\text { Roupa }\end{array}$ & $\begin{array}{c}\text { Pia } \\
\text { Cozinha }\end{array}$ & Descarga & $\begin{array}{c}\text { Uso } \\
\text { Externo }\end{array}$ & $\begin{array}{c}\text { TOTAL / } \\
\text { litros }\end{array}$ \\
\hline $\begin{array}{c}\text { Quantidade de Água } \\
\text { Utilizada / litros }\end{array}$ & 5 & 126 & 23 & 73 & 93 & 94 & 6 & 420 \\
\hline
\end{tabular}

Fonte: Cohim e Cajazeiras (dados não publicados)

Analisou-se o uso conjunto de três fontes alternativas, além da água de abastecimento público: água de chuva, água cinza e água subterrânea, os valores de intensidade energética de cada uma delas é mostrado na Tabela 2:

Tabela 2- Intensidades energéticas das fontes variadas de água para consumo doméstico Intensidades Energéticas / $\left(\mathrm{kwh} / \mathrm{m}^{3}\right)$

\begin{tabular}{cccc}
\hline Sistema Público & Água de Chuva & Água Subterrânea & Água Cinza \\
\hline 3,51 & 0,8 & 0,6 & 1,2 \\
\hline
\end{tabular}

Fonte: Elaborado pelos autores a partir de revisão bibliográfica. 
Os usos admitidos para as fontes analisadas são mostrados na Tabela 3. A combinação de fontes e usos pressupõe uma qualidade de cada fonte compatível com o uso associado, embora não tenha sido realizada uma avaliação de risco para respaldar tal decisão.

Os limites de utilização de cada fonte foram definidos de acordo com os seguintes:

- Água do sistema público: ilimitado;

- Água de chuva: média de $115 \mathrm{~L} /$ dia, obtido pelo método do balanço seriado para o período de 1998 a 2012, com uma cisterna de $1500 \mathrm{~L}$;

- Água subterrânea: $180 \mathrm{~L} /$ dia, admitindo-se a recarga através da área permeável;

- Água cinza: $199 \mathrm{~L} /$ dia, correspondente à produção do chuveiro somada à da lavação de roupa.

Então, temos na Tabela 3, as fontes disponíveis associadas aos usos em uma residência:

Tabela 3- Quadro de fontes x usos da água em uma residência

\begin{tabular}{ccccc}
\hline \multirow{2}{*}{ USOS } & \multicolumn{5}{c}{ FONTES } \\
\cline { 2 - 5 } & Sistema Público & Água de Chuva & Água Subterrânea & Água Cinza \\
\hline Beber & $\mathrm{x}$ & $\mathrm{x}$ & $\mathrm{X}$ & \\
\hline Chuveiro & $\mathrm{x}$ & $\mathrm{x}$ & $\mathrm{X}$ & \\
\hline Lavatório & $\mathrm{x}$ & $\mathrm{x}$ & $\mathrm{X}$ & \\
\hline Lav. Roupa & $\mathrm{x}$ & $\mathrm{x}$ & $\mathrm{X}$ & $\mathrm{X}$ \\
\hline Pia de Cozinha & $\mathrm{x}$ & $\mathrm{x}$ & $\mathrm{X}$ & $\mathrm{X}$ \\
\hline Descarga & $\mathrm{x}$ & $\mathrm{x}$ & $\mathrm{X}$ & \\
\hline Uso Externo & $\mathrm{x}$ & & & \\
\hline
\end{tabular}

Fonte: Elaborado pelos autores a partir de revisão bibliográfica.

As parcelas atribuídas a cada fonte e o volume total utilizado (soma das parcelas) foram modeladas pelas equações 1 a 7 :

$\begin{array}{ll}a_{1} * U_{1}=U_{1} \text { total } & \text { Eq. (1) } \\ b_{1} * U_{2}+b_{2} * U_{2}+b_{3} * U_{2}=U_{2} \text { total } & \text { Eq. (2) } \\ c_{1} * U_{3}+c_{2} * U_{3}+c_{3} * U_{3}=U_{3} \text { total } & \text { Eq. (3) } \\ d_{1} * U_{4}+d_{2} * U_{4}+d_{3} * U_{4}=U_{4} \text { total } & \text { Eq. (4) } \\ e_{1} * U_{5}+e_{2} * U_{5}+e_{3} * U_{5}=U_{5} \text { total } & \text { Eq. (5) } \\ f_{1} * U_{7}+f_{2} * U_{7}+f_{3} * U_{7}+f_{4} * U_{7}=U_{7} \text { total } & \text { Eq. (6) } \\ g_{1} * U_{6}+g_{2} * U_{6}+g_{3} * U_{6}+g_{4} * U_{6}=U_{6} \text { total } & \text { Eq. (7) }\end{array}$

As variáveis de a a $\mathbf{g}$ correspondem aos usos relacionados na Tabela 3, de Beber a Uso Externo, e os índices de 1 a 4 correspondem às fontes relacionadas na Tabela 3, de Sistema Público de Abastecimento a Água Cinza, nessa ordem.

O objetivo do modelo é minimizar a função definida como o produto da fonte de água e a respectiva energia incorporada definida na Equação 8.

MinUE $=\sum_{i=1}^{4}\left(a_{i} * U_{1}+b_{i} * U_{2}+c_{i} * U_{3}+d_{i} * U_{4}+e_{i} * U_{5}+f_{i} * U_{6}+g_{i} * U_{7}\right)$

Com i variando de 1 a 4 de acordo com as fontes e E representa o valor de energia incorporada em cada fonte (Tabela1).

Adicionalmente, foram estabelecidas restrições correspondentes aos volumes máximos utilizáveis de cada fonte.

$$
\begin{array}{rr}
a_{2} * U_{1}+b_{2} * U_{2}+c_{2} * U_{3}+d_{2} * U_{4}+e_{2} * U_{5}+f_{2} * U_{6}+g_{2} * U_{7} \leq M \text { áxchuva } \\
a_{3} * U_{1}+b_{3} * U_{2}+c_{3} * U_{3}+d_{3} * U_{4}+e_{3} * U_{5}+f_{3} * U_{6}+g_{3} * U_{7} \leq M \text { áxsubt } \\
a_{4} * U_{1}+b_{4} * U_{2}+c_{4} * U_{3}+d_{4} * U_{4}+e_{4} * U_{5}+f_{4} * U_{6}+g_{4} * U_{7} \leq M \text { áxcinza } \\
U_{1} \text { total }=U_{1} & \text { Eq. (12) } \\
U_{2} \text { total }=U_{2} & \text { Eq. (13) } \\
U_{3} \text { total }=U_{3} & \text { Eq. (14) } \\
U_{4} \text { total }=U_{4} & \text { Eq. (15) } \\
U_{5} \text { total }=U_{5} & \text { Eq. (16) } \\
U_{6} \text { total }=U_{6} & \text { Eq. (17) }
\end{array}
$$


As variáveis de a a $\mathbf{g}$ correspondem aos usos relacionados na Tabela 3, de Beber a Uso Externo, e os índices de 2 a 4 são as correspondências com as fontes da Tabela 3, de Água de Chuva a Água Cinza; U corresponde ao volume de água utilizado por cada aparelho segundo revisão bibliográfica e varia de 1 a 7 (de acordo com a Tabela 3, essa sequência vai de Beber a Uso Externo, na ordem), por fim, $\mathbf{U}_{\text {total }}$, que corresponde ao volume total encontrado para cada uso antes da otimização.

\section{RESULTADOS E/OU DISCUSSÃO}

Após otimização, foram encontrados os valores correspondentes às parcelas utilizadas por cada fonte a fim de obter a redução do consumo de água da concessionária. Essas porcentagens podem ser observadas abaixo na Tabela 4:

Tabela 4- Porcentagens correspondentes aos usos de cada fonte

\begin{tabular}{cccccc}
\hline Usos & Sistema público & Água de Chuva & Água Subterrânea & Água Cinza & Quantidade total / (L) \\
\hline Beber & $100 \%$ & $0 \%$ & $0 \%$ & $0 \%$ & 5 \\
\hline Chuveiro & $0 \%$ & $33 \%$ & $68 \%$ & $0 \%$ & 126 \\
\hline Lavatório & $27 \%$ & $35 \%$ & $38 \%$ & $0 \%$ & 23 \\
\hline Lav. Roupa & $13 \%$ & $37 \%$ & $49 \%$ & $0 \%$ & 73 \\
\hline Pia de cozinha & $4 \%$ & $42 \%$ & $54 \%$ & $0 \%$ & 93 \\
\hline Descarga & $0 \%$ & $0 \%$ & $0 \%$ & $100 \%$ & 94 \\
\hline Uso externo & $0 \%$ & $0 \%$ & $0 \%$ & $100 \%$ & 6 \\
\hline
\end{tabular}

Fonte: Elaborado pelos autores.

A partir do quadro de Fontes e Usos (Tabela 3) em que foram atribuídas as fontes que poderiam ser utilizadas em cada uso final de uma residência e, com a intenção da redução do consumo de água do sistema público, os valores obtidos na Tabela acima referem-se à porcentagem do consumo de água para cada fonte priorizando as fontes alternativas de abastecimento. Logo, percebe-se que para alguns usos, o consumo de água do sistema público correspondeu a $0 \%$ e o consumo de água cinza, por exemplo, a 100\%, confirmando a redução do consumo da água da concessionária.

Analisando o esquema acima em que são consideradas as entradas e utilização de todas as fontes em uma residência, nota-se a redução do consumo de água potável vinda do Sistema de Abastecimento Público de Água a partir do uso das outras fontes disponíveis (Tabela 4). Esses consumos variam mensalmente devido à disponibilidade, principalmente da água pluvial que varia com a precipitação de cada estação do ano. A água subterrânea apresentou valores constantes. O consumo em litros utilizado por cada fonte para a minimização do uso da água vinda da concessionária pode ser observado na Tabela 5:

Tabela 5- Volumes utilizados por cada fonte em uma residência

\begin{tabular}{lcccc}
\hline Mês & Sistema Público / Litros & Água de Chuva / Litros & Água Subterrânea / Litros & Água Cinza / Litros \\
\hline Jan & 35 & 105 & 180 & 100 \\
\hline Fev & 37 & 103 & 180 & 100 \\
\hline Mar & 56 & 84 & 180 & 100 \\
\hline Abr & 17 & 123 & 180 & 100 \\
\hline Mai & 5 & 183 & 180 & 52 \\
\hline Jun & 5 & 204 & 180 & 31 \\
\hline Jul & 5 & 161 & 180 & 74 \\
\hline Ago & 9 & 131 & 180 & 100 \\
\hline Set & 56 & 84 & 180 & 100 \\
\hline Out & 64 & 76 & 180 & 100 \\
\hline Nov & 38 & 102 & 180 & 100 \\
\hline Dez & 63 & 77 & 180 & 100 \\
\hline
\end{tabular}

Fonte: Elaborado pelos autores

Na Tabela acima nota-se que o consumo de água cinza foi priorizado já que esta é uma fonte que possui qualidade inferior às demais disponíveis. Nos meses de maio, junho e julho, que 
apresentam maior precipitação e consequentemente maior disponibilidade de água de chuva, o consumo de água cinza é reduzido.

Como visto na Tabela 5, o consumo de água potável vinda do Sistema de Abastecimento Público de Água foi reduzido, consequentemente, já que são recursos inter-relacionados, a intensidade energética quando comparada ao uso somente da água de abastecimento $(47,4 \mathrm{kWh})$ também foi reduzida, as reduções também variam mensalmente. Isso pode ser analisado na Tabela 6 , abaixo:

Tabela 6- Reduções de água e energia encontradas para o sistema proposto

\begin{tabular}{cccc}
\hline Mês & Energia considerando todas as fontes (Kwh) & Redução de energia & Redução de água \\
\hline Jan & 13,05 & $72 \%$ & $92 \%$ \\
\hline Fev & 13,21 & $72 \%$ & $91 \%$ \\
\hline Mar & 14,75 & $69 \%$ & $87 \%$ \\
\hline Abr & 11,58 & $76 \%$ & $96 \%$ \\
\hline Mai & 10,03 & $79 \%$ & $99 \%$ \\
\hline Jun & 9,78 & $79 \%$ & $99 \%$ \\
\hline Jul & 10,29 & $78 \%$ & $99 \%$ \\
\hline Ago & 10,93 & $77 \%$ & $98 \%$ \\
\hline Set & 14,75 & $69 \%$ & $87 \%$ \\
\hline Out & 15,4 & $67 \%$ & $85 \%$ \\
\hline Nov & 13,29 & $72 \%$ & $91 \%$ \\
\hline Dez & 15,32 & $68 \%$ & $85 \%$ \\
\hline MÉDIA/MÊS & 12,7 & $73 \%$ & $92 \%$ \\
\hline
\end{tabular}

Fonte: Elaborado pelos autores.

Com o arranjo proposto otimizado, a energia incorporada média foi de $1,0 \mathrm{kWh} / \mathrm{m}^{3}$, equivalente a $29 \%$ da correspondente à do sistema público que é igual a $3,51 \mathrm{kWh} / \mathrm{m}^{3}$.

\section{CONSIDERAÇÕES FINAIS}

A minimização do consumo de água vinda da concessionária e do encargo energético aliado à mesma é de extrema importância nos dias atuais por se tratar de um recuso em situação de escassez em algumas regiões. Com o objetivo de atender às necessidades de consumo de água de forma para as gerações atuais e futuras, é fundamental a gestão sustentável dos recursos hídricos. Isso pode ser feito através da otimização da eficiência do uso da água através da implantação de sistemas alternativos de consumo, preservando assim os ecossistemas naturais.

Buscando essa minimização e após a aplicação da metodologia proposta, nota-se que o consumo de água das fontes alternativas foram priorizadas nos usos aos quais poderiam ser destinadas. Isso pode ser visto, por exemplo, no consumo de água cinza, que podendo ser utilizada para fins como Descarga e Uso Externo, supriu $100 \%$ da demanda destas, reduzindo a quantidade de água do sistema público que seria demandada caso o a utilização de água cinza não fosse integrada ao sistema. O mesmo aconteceu para as demais fontes e seus respectivos usos.

A redução mensal do consumo da água do sistema de abastecimento público foi satisfatória, tendo uma variação de $85 \%$ em dezembro a 99\% nos meses de maio, junho e julho e, quanto ao consumo energético, essa redução variou de $67 \%$ em outubro a $79 \%$ nos meses de maio e junho. A média de redução alcançada com o sistema proposto foi de $73 \%$ para redução de energia e 92\% para redução de água da concessionária, garantindo a eficiência do sistema.

\section{REFERÊNCIAS}

[1] RENOUF, M. A. et al. Urban metabolism for planning water sensitive cities: Concept for an urban water metabolism evaluation framework. Melbourne, Australia: Research Centre For Water Sensitive Cities, 2016. 43 p.

[2] SNIS-Sistema Nacional de Informações sobre Saneamento; Diagnóstico dos Serviços de Água e Esgotos - 2016. Ministério das Cidades. Secretaria Nacional de Saneamento Ambiental. Brasília, Fevereiro - 2018.

[3] SOARES, R. B., MEMELli, M. S., ROQUE, R. P., GONÇALVES, R. F. Comparative Analysis of the Energy Consumption of Different Wastewater Treatment Plants. International Journal of Architecture, Arts and Applications.Vol.3, No. 6, 2017, pp. 79-86. 2017 